\title{
Shape changes in static V-P loops from children's lungs related to growth
}

\author{
DAVID G. FAGAN
}

From the Department of Pathology, The Hospital for Sick Children, Toronto, Ontario, Canada

\begin{abstract}
Fagan, D. G. (1977). Thorax, 32, 198-202. Shape changes in static V-P loops from children's lungs related to growth. Sixty-eight sets of deflation data from the left lungs of children who had died from non-pulmonary causes were analysed by the exponential equation model to derive theoretical values of Pst(1) for 50, 60, and $90 \%$ of the observed maximum inflation volume. The resultant $P_{50},{ }_{60}$, and 90 values were compared to the same values measured from graphic displays of the V-P data. The graphically derived Pst(1) data at 50, 60, and $90 \%$ of TLC were then plotted against the crown-heel length to demonstrate a shape change related to physical growth.

It was found that the form of the deflation curve in preterm infants did not fit an exponential model as satisfactorily as did the deflation curve from older children. The exponential model should be used with caution in small infants where Pst(1) values below $\mathbf{P}_{90}$ are sought. A maximum inflation pressure of $+30 \mathrm{~cm} \mathrm{H}_{2} \mathrm{O}$ was found to produce a $V_{\max }$ within $98 \%$ of the hypothetical Vinr value.
\end{abstract}

The question whether there is a growth-related shape change in static pulmonary volume pressure (V-P) deflation curves has to some extent been confused by the different methods of data presentation used in human postmortem data (Fagan, 1969; Stigol et al., 1972; Fagan, 1976), animal experiments (Havránková and Kuncová, 1971), and clinical studies (Turner et al., 1968; Zapletal et al., 1971; Zapletal et al., 1976), and differences in the level of inflation which was regarded as equivalent to in-vivo maximum lung capacity (TLC).

A method of V-P loop analysis, developed by Salazar and Knowles (1964), is finding increasing application in experimental animal and in-vivo human experiments (Turner et al., 1968; Glaister et al., 1973; Mansell et al., 1977) because it does not depend on an arbitrary TLC.

This method involves a mathematical analysis to fit an exponential equation to the observed deflation data, and from this to predict the static elastic recoil pressure (Pst(1)), at given proportions of TLC.

In this paper the V-P data collected by the methods described in a previous communication (Fagan, 1976) from children's lungs obtained at necropsy, with body lengths ranging from 33 to $168 \mathrm{~cm}$, are analysed by the exponential regression method described by Salazar and Knowles (1964). The results of this analysis are compared with the results from measurement of the same Pst(1) values from the same data displayed graphically. The graphically derived Pst(1) data are then $\underset{x}{\tilde{x}}$ analysed by linear regression to demonstrate $\mathrm{a}_{\sigma}$ change in Pst(1) at $50 \%, 60 \%$, and $90 \%$ TLC $\left(P_{50}, P_{60}\right.$, and $\left.P_{90}\right)$ related to increasing physicalo stature.

This constitutes evidence for a growth-relatedo deflation curve shape change where a shape change is defined as a change in Pst(1) at a giveno proportion of maximum inflation volume.

\section{Material and methods}

The left lung was reserved at necropsy in a series of infants and children who had died from nonpulmonary causes. The lungs were inflated an deflated in a stepped manner using fixed pressures intervals to obtain static V-P data. The full details of the methods, population, and controls are described in a previous communication (Fagan $\mathbb{Q}$ 1976). The standard maximum inflation pressure was $+30 \mathrm{~cm} \mathrm{H}_{2} \mathrm{O}$. The deflation V-P data fromf each of the 74 lungs designated normal aftek subsequent histological examination were analyse $B$ 
to find a 'best fit' single exponential equation using an iterative procedure on a HewlettPackard 9810A computer.

The form of the equation used was $V=V_{I N F}\left(l-e^{-K r}\right)$, where $V=$ the observed lung volume, $V_{\text {INF }}=$ the volume asymptote, or the theoretical volume of the lung at infinitely high pressure, $P=P s t(1)$ at the observed lung volume, and $\mathrm{K}=\mathrm{a}$ constant.

Of the 74 lungs designated normal, three were excluded from the series because the computer failed to find a solution within 10 minutes, two were excluded because the solution found had a correlation coefficient value (r) of $<0.97$, and one was excluded because less than four values had been recorded during deflation. A further three values from each regression analysis were deleted as being unusually high or low.

The solution was then used to predict $P_{50}, 60$, ${ }_{70}, 80$, and ${ }_{90}$, that is, Pst(1) at $50 \%, 60 \%, 70 \%$, $80 \%$, and $90 \%$ of the observed $V_{\max }$ of the left lung. In order to compare data obtained by the exponential and graphic methods, mean values of sets of grouped deflation data were plotted, and the $\mathbf{P}_{50},{ }_{60},{ }_{70},{ }_{80}$, and ${ }_{90}$ were read off the resultant curve when the individual points were joined by a free-hand smoothed curve and by straight lines.

When these results were scrutinised, some of the preterm and full-term infant group results were re-computed with and without observed volume values at zero transpulmonary pressure (Vo).

\section{Results}

The mean correlation coefficient and standard deviation for all 68 deflation curves were analysed exponentially, $\mathrm{r}=0.995, \mathrm{SD}=0.005$.

The ratio $\frac{V_{\max }}{V_{\text {INF }}}$ was calculated to ascertain whether the observed $\mathrm{V}_{\max }$ using a transpulmonary pressure of $+30 \mathrm{~cm} \quad \mathrm{H}_{2} \mathrm{O}$ approached the asymptote, $\mathrm{V}_{\text {INF. }}$. The resultant mean was $\mathrm{V}_{\max }=$ $0.993 \mathrm{~V}_{\mathrm{INF}}, \mathrm{SD} \pm 0.005$. The individual results were plotted against body length, and linear regression analysis failed to show any change related to body length.

In Fig. 1 the deflation data from group $A$ of Table 1 are plotted with \pm 1 SD. Since no significant difference between Pst(1) values from freehand smoothing of the curve and straight line joining of the six points shown could be demonstrated (Table 2), the straight line is illustrated (Figs 1 and 2).

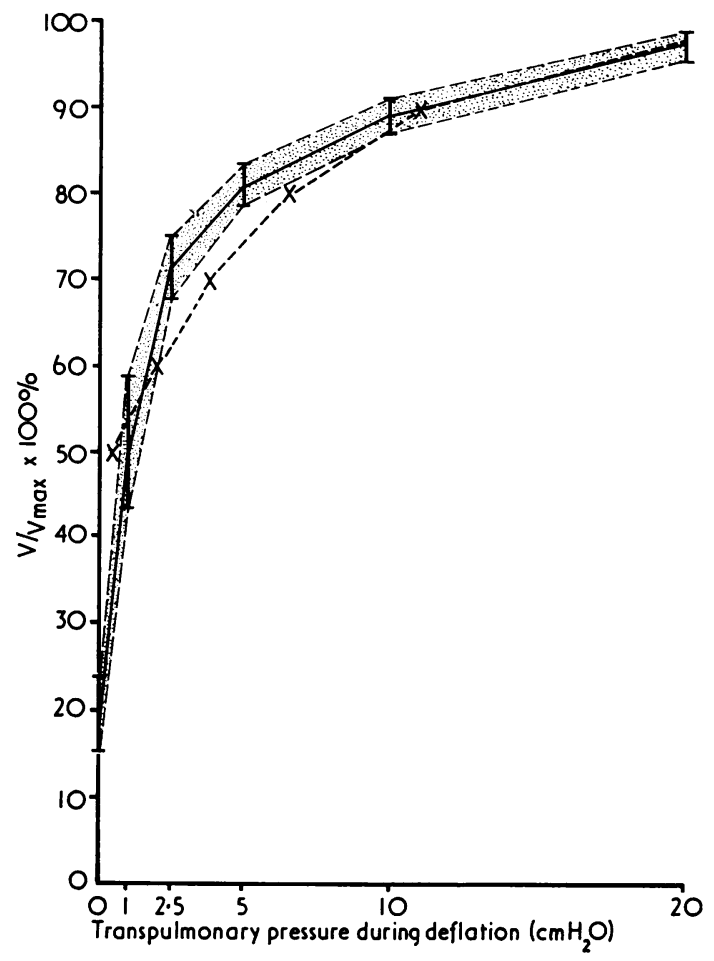

Fig. 1 The mean deflation curve data from group $A$, Table 1, are plotted against the transpulmonary pressure. The shaded area indicates $\pm 1 S D$ around each mean datum point. The datum points have been joined by straight lines. The second curve $x---x$ results from finding the 'best fit' exponential regression equation and using that to predict the Pst(l) values shown at $V_{50},{ }_{60},{ }_{70},{ }_{80}$, and ${ }_{90}$. In this pooled example, correlation coefficient, $r,=0.989$.

It can be seen that the mean expontial $\mathbf{P}_{50} 60$, and ${ }_{90}$ values all lie close to or within 1 standard deviation of the mean of the observed data, while the $P_{70}$ and ${ }_{80}$ values deviate beyond that limit. The results of the re-analysis of group A values without the Vo data are shown in Table 2.

In Fig. 2 the mean data from group D, Table 1, are plotted in the same fashion as in Figure 1. All the exponential Pst(1) values now lie within 1 standard deviation about the mean observed values.

Figure 3 shows the graphic $P_{90}$ values plotted against the body length $(\mathrm{CH})$ in centimetres, with $95 \%$ confidence limits. The linear regression equation: $P_{90}=0.067(\mathrm{CH})+8 \cdot 14, \mathrm{SD} \pm 2 \cdot 59, \mathrm{r}=0.66$, $\mathrm{P}<0.001$.

Figure 4 shows the $P_{60}$ values plotted against the body length, again with $95 \%$ confidence limits. $P_{60}=0.045(\mathrm{CH})+0.62, \mathrm{SD} \pm 1.43, \mathrm{r}=0.79, \mathrm{P}<0.001$. 


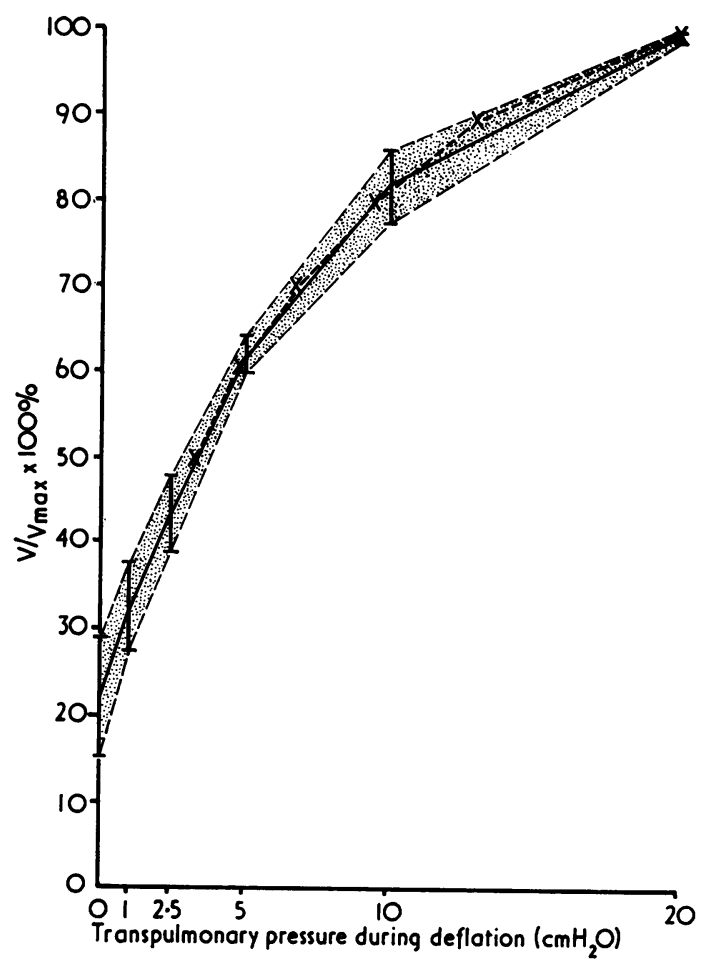

Fig. 2 Shows the mean deflation curve data from group $D$, Table 1 , plotted in the same manner as in Fig. 1, with the second curve $x---x$ derived in the same manner as in Figure 1. In this example, $r=0.999$.

Figure 5 shows the $\mathbf{P}_{50}$ values plotted against the body length with $95 \%$ confidence limits. $\mathrm{P}_{50}=0.032(\mathrm{CH})+0.27, \mathrm{SD} \pm 0.99, \mathrm{r}=0.82, \mathrm{P}<0.001$.

\section{Discussion}

Despite the high degree of mathematical correlation between the Pst(1) values in the pre-term (and some full-term) neonates, the theoretical curve is not a good fit (Fig. 1) as the predicte $\overrightarrow{\vec{b}}$ values go in runs above and below the observe $\phi$ data curve.

It is unfortunate that much of the information required from this form of analysis is in the are of maximum deviation. In the pre-term group (group A, Table 1), the Pst(1) values $P_{70}$ and ${ }_{80}$ deviate widely from the observed values while the $P_{50}{ }_{60}$, and ${ }_{90}$ values lie on or within \pm 1 SD of the observed mean.

In addition to this problem, the amount of low $\overrightarrow{\frac{\vec{D}}{x}}$ pressure inflation data (Table 2) required to pro duce the 'best fit' exponential predictions of $P_{s}$ and ${ }_{60}$ must raise serious questions about the application of this method of V-P analysis in smato infants.

The two valuable points about this method are. that the predicted $\mathbf{P}_{90}$ values seem to lie very close to the graphically derived $\mathbf{P}_{90}$ values whether ex: tended low-pressure data are available or not, and that the arbitrarily selected $\mathrm{P}_{\max }+30 \mathrm{~cm} \mathrm{H}_{2} \mathrm{O}$ gives a $V_{\max }$ close to the asymptote.

It is also noteworthy that the exponential dat from the older infants and children conform closely to the graphically derived data.

The $P_{50}$ and ${ }_{60}$ values (Figs 4 and 5) show the् same high degree of correlation $(P<0.001)$, with body length as the $P_{90}$, although scrutiny of the slope of the regression lines suggests that the rato of change with growth of the $P_{50}$ and ${ }_{60}$ is differ ent from that of the $P_{90}$ values. At the presen time it is uncertain if this is an artefact due to the mode of analysis or whether it suggests that the growth-related determinants of the $P_{50}$ and ${ }_{60}$ are different from those of the $\mathbf{P}_{90}$.

The failure of the Salazar and Knowles form of equation to fit the small infant deflation curve adequately with progressive improvement of the 'adequacy of fit' with increasing stature suggest that a growth-related modification of the equation is possible, and this of itself in conjunction wite. the differences of slope of the $P_{50},{ }_{60}$, and of regression equation suggests that more complex

Table 1 Data from the 68 cases grouped according to body length

\begin{tabular}{|c|c|c|c|c|c|}
\hline & Group $A$ & Group B & Group $C$ & Group D & Group $E$ \\
\hline $\begin{array}{l}\text { Body length (cm) } \\
\text { Number of cases } \\
\text { Mean } V_{20}(\%) \\
\text { Mean } V_{10} \\
\text { Mean } V_{5} \\
\text { Mean } V_{2 \cdot 5} \\
\text { Mean } V_{1 \cdot 0} \\
\text { Mean } V_{0}\end{array}$ & $\begin{array}{l}30-45 \\
8 \\
97 \cdot 0 \pm 1 \cdot 5 \\
89 \cdot 30 \pm 2 \cdot 1 \\
81 \cdot 0 \pm 2 \cdot 2 \\
71 \cdot 40 \pm 3 \cdot 7 \\
50 \cdot 90 \pm 7 \cdot 8 \\
19 \cdot 70 \pm 4 \cdot 4\end{array}$ & $\begin{array}{l}46-55 \\
26 \\
96 \cdot 20 \pm 1 \cdot 36 \\
87 \cdot 60 \pm 2 \cdot 5 \\
77 \cdot 40 \pm 4 \cdot 1 \\
61 \cdot 10 \pm 8 \cdot 4 \\
41 \cdot 10 \pm 7 \cdot 4 \\
23 \cdot 60 \pm 9 \cdot 1\end{array}$ & $\begin{array}{l}56-65 \\
13 \\
96 \cdot 0 \pm 1 \cdot 4 \\
82 \cdot 0 \pm 4 \cdot 1 \\
65 \cdot 30 \pm 3 \cdot 8 \\
48 \cdot 30 \pm 5 \cdot 2 \\
32 \cdot 10 \pm 6 \cdot 6 \\
18 \cdot 70 \pm 7 \cdot 3\end{array}$ & $\begin{array}{l}66-90 \\
13 \\
96 \cdot 3 \pm 1 \cdot 5 \\
81 \cdot 8 \pm 4 \cdot 0 \\
62 \cdot 8 \pm 2 \cdot 4 \\
43 \cdot 7 \pm 4 \cdot 3 \\
32 \cdot 9 \pm 5 \cdot 0 \\
22 \cdot 2 \pm 7 \cdot 0\end{array}$ & $\begin{array}{l}91-168 \\
8 \\
96 \cdot 2 \pm 0 \cdot 95 \\
79 \cdot 4 \pm 6 \cdot 59 \\
59 \cdot 1 \pm 5 \cdot 89 \\
43 \cdot 6 \pm 9 \cdot 1 \\
-\end{array}$ \\
\hline
\end{tabular}

The mean $\mathrm{V}$ values are presented as percentages of the $\mathrm{V}_{\mathrm{max}}, \pm 1$ standard deviation at pulmonary pressure in $\mathrm{cm}_{\mathrm{H}} \mathrm{O}$, indicated by the suffix Thus $\mathrm{V}_{8}=$ volume at $+5 \mathrm{~cm} \mathrm{H}_{2} \mathrm{O}$ during defiation maximum inflation volume, $\times 100 \%$. 
Table 2 Pst(I) values at 50,60, and $90 \%$ of $V_{\max }$ estimated by exponential function and graphic analysis for three groups shown in Table 1

\begin{tabular}{|c|c|c|c|c|c|c|c|c|c|}
\hline \multirow[t]{2}{*}{ Mean values of } & \multicolumn{3}{|c|}{ Group A } & \multicolumn{3}{|c|}{ Group B } & \multicolumn{3}{|c|}{ Group D } \\
\hline & $P_{50}$ & $P_{\text {so }}$ & $P_{90}$ & $P_{50}$ & $P_{\text {so }}$ & $P_{90}$ & $P_{\text {so }}$ & $P_{\text {co }}$ & $P_{00}$ \\
\hline $\begin{array}{l}\text { Exponential with } V_{0} \text { data } \\
\text { Exponential without } V_{0} \text { data } \\
\text { Graphic smooth mean curve } \\
\text { Graphic straight line mean curve }\end{array}$ & $\begin{array}{r}0.61 \\
-0.85 \\
0.99 \\
0.99\end{array}$ & $\begin{array}{l}2 \cdot 06 \\
0 \cdot 84 \\
1 \cdot 50 \\
1 \cdot 70\end{array}$ & $\begin{array}{l}10 \cdot 98 \\
11 \cdot 09 \\
10 \cdot 95 \\
11 \cdot 05\end{array}$ & $\begin{array}{l}1.48 \\
0.72 \\
1.55 \\
1.65\end{array}$ & $\begin{array}{l}3 \cdot 06 \\
2 \cdot 39 \\
2 \cdot 3 \\
2 \cdot 4\end{array}$ & $\begin{array}{l}12 \cdot 62 \\
12 \cdot 46 \\
12 \cdot 2 \\
13 \cdot 1\end{array}$ & $\begin{array}{l}3 \cdot 17 \\
3 \cdot 17 \\
3 \cdot 30 \\
3 \cdot 35\end{array}$ & $\begin{array}{l}4 \cdot 74 \\
4 \cdot 73 \\
4 \cdot 8 \\
4 \cdot 8\end{array}$ & $\begin{array}{l}14 \cdot 13 \\
14 \cdot 10 \\
14 \cdot 85 \\
15 \cdot 73\end{array}$ \\
\hline
\end{tabular}

All pressures are in $\mathrm{cm} \mathrm{H}_{2} \mathrm{O}$.

The exponential values of $P_{50}, P_{60}$, and $P_{90}$ using $V_{0}$ data lie close to or within the range of the mean of the observed values, \pm 1 SD (see Fig. 1). The exponential values derived without the $V_{0}$ data at $P_{50}$ and $P_{80}$ of group $A$, and $P_{50}$ of group $B$, lie well outwith the range of \pm 1 SD about the observed means.

There seems to be little difference in the estimates derived by the different graphic analyses.

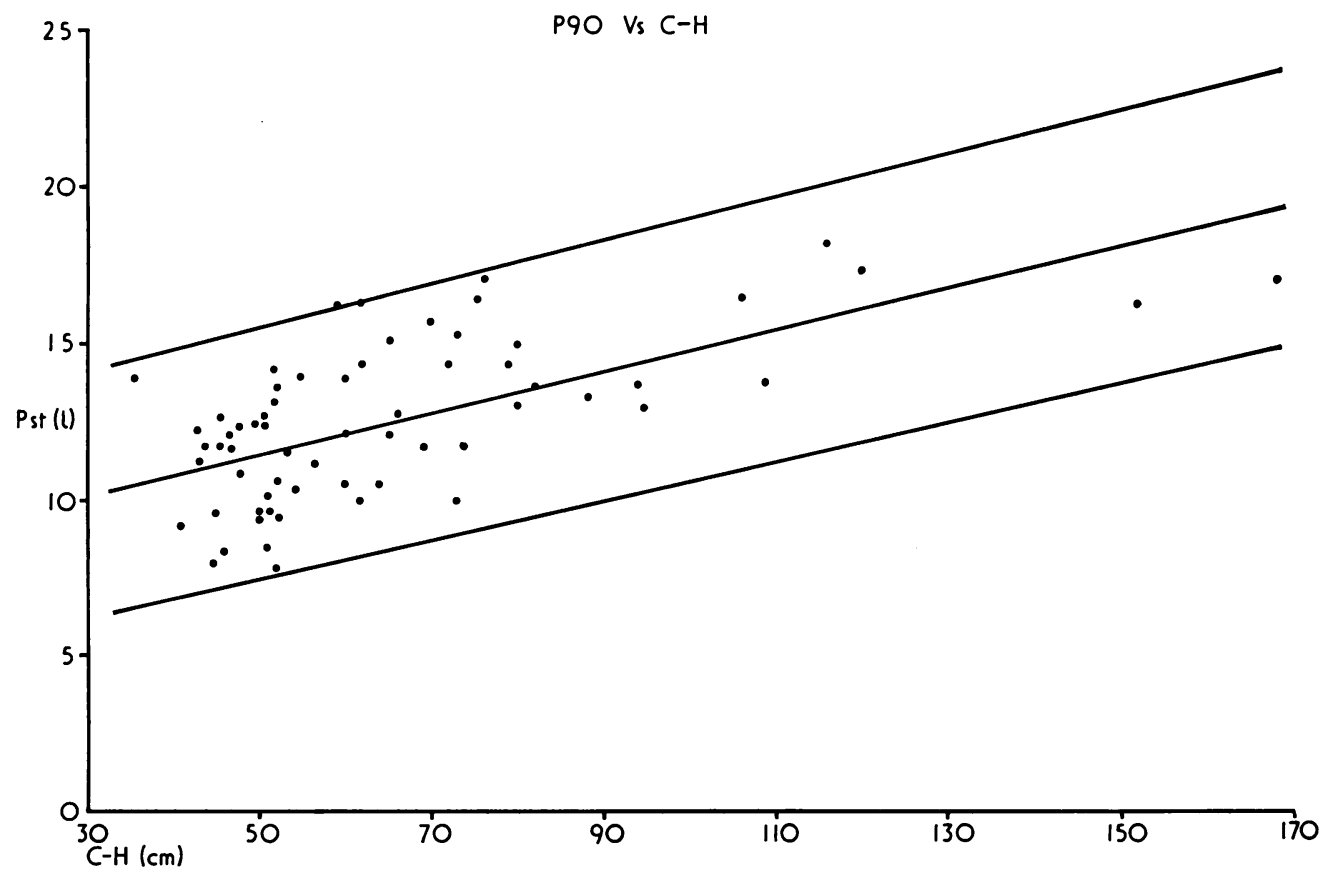

Fig. 3 Shows the linear regression equation from plotting the individual $P_{90}$ values obtained by graphic analysis against the crown-heel length: $Y=0.067 X+8.14, \pm 2.59, r=0.66, \mathrm{P}<0.001$.

changes of shape or form of the deflation V-P curve may be occurring in this period as well as the basic fact of a growth-related increase in static recoil at the inflation levels described.

This analysis shows that the changes seen in V-P loop shape when plotted in the proportional manner (Fagan, 1969; Havránková and Kuncová, 1971; Fagan, 1976) are quite consistent with the changes reported by Turner et al. (1968), Zapletal et al. (1971), and Zapletal et al. (1976), whether the index of development chosen is body length, maximum inflation volume, or body weight over the whole of the growth range studied.

I am indebted to the Department of Pulmonary Physiology, the Hospital for Sick Children, Toronto, for the use of their facilities, and, in particular, to Dr. A. Mansell for his patient tuition and encouragement, and to D. Pengelly for programming the H-P $9810 \mathrm{~A}$.

I am further indebted to Dr. M. M. Wood, Chief of the Department of Bio-Statistics, Hospital for Sick Children, Toronto, for invaluable advice on the statistical methods and the interpretation of the results. 


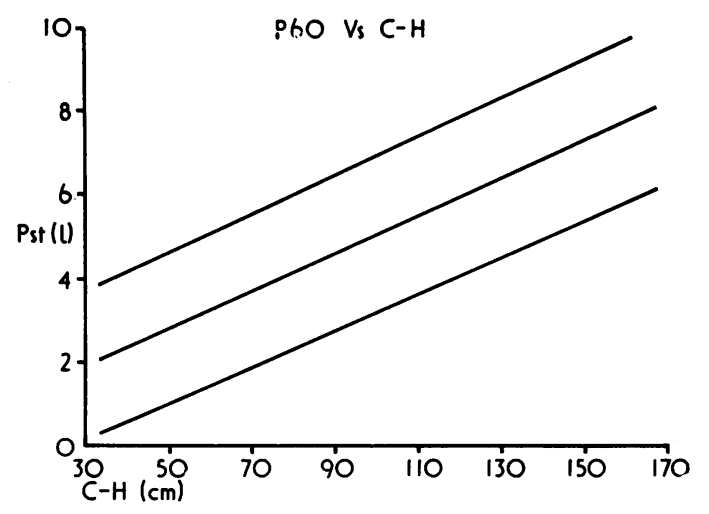

Fig. 4 Shows the linear regression equation from plotting the individual $P_{60}$ values obtained by graphic analysis against the crown-heel length: $Y=0.045$ $X+0.62, \pm 1.43, r=0.79, \mathrm{P}<0.001$.

\section{References}

Fagan, D. G. (1969). Functional development of the human lung. In The Anatomy of the Developing Lung, edited by J. L. Emery, p. 191. Heinemann, London.

Fagan, D. G. (1976). Post-mortem studies of the semistatic volume-pressure characteristics of infants' lungs. Thorax, 31, 534-543.

Glaister, D. H., Schroter, R. C., Sudlow, M. F., and Milic-Emili, J. (1973). Bulk elastic properties of excised lungs and the effect of a transpulmonary pressure gradient. Respiration Physiology, 17, 347364.

Havránková, J. and Kuncová, M. (1971). Der Einfluss des Körpergewichtes auf die statischen Druckvolumen-Diagramme isolierter Rattenlungen. Respiration, 28, 186-196.

Mansell, A., Bryan, C., and Levison, H. (1977). Relationship of lung recoil to lung volume and maximum expiratory flow in normal children. Journal of Applied Physiology (in press).

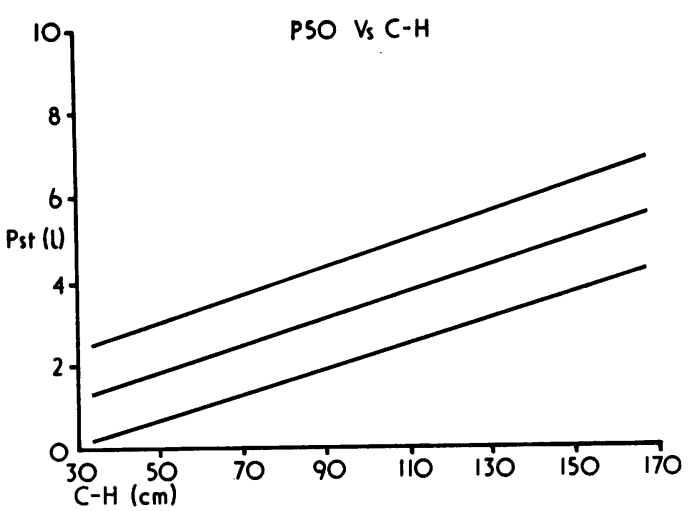

Fig. 5 Shows the linear regression equation from plotting the individual $P_{50}$ values obtained by graphic analysis against the crown-heel length: $Y=0.032$ $X+0.27, \pm 0.99, r=0.82, \mathrm{p}<0.001$.

Salazar, E. and Knowles, J. H. (1964). An analysis of $\vec{\theta}$ pressure-volume characteristics of the lungs. . Journal of Applied Physiology, 19, 97-104.

Stigol, L. C., Vawter, G. F., and Mead, J. (1972). Studies on elastic recoil of the lung in a pediatric population. American Review of Respiratory Disease, 105, 552-563.

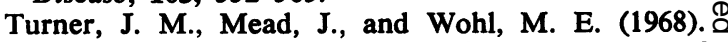
Elasticity of human lungs in relation to age. Journal $\overrightarrow{\vec{A}}$ of Applied Physiology, 25, 664-671.

Zapletal, A., Misur, M., and Samánek, M. (1971). Static recoil pressure of the lungs in children. Bulletin de Physio-Pathologie Respiratoire, 7, 139147.

Zapletal, A., Paul, T., and Samánek, M. (1976). Pulmonary elasticity in children and adolescents. $x$ Journal of Applied Physiology, 40, 953-961.

Requests for reprints to: Dr. D. G. Fagan, Department of Pathology, The Hospital for Sick Children, 555 University Avenue, Toronto, Ontario, Canada윽 M5G 1 X8. 